\title{
A Portable Low-Power Acquisition System with a Urease Bioelectrochemical Sensor for Potentiometric Detection of Urea Concentrations
}

\author{
Wei-Jhe Ma ${ }^{1}$, Ching-Hsing Luo ${ }^{1,2, *}$, Jiun-Ling Lin ${ }^{3}$, Sin-Houng Chou ${ }^{3}$, Ping-Hung Chen ${ }^{3}$, \\ Mei-Jywan Syu ${ }^{3}$, Shin-Hung Kuo ${ }^{1}$ and Shin-Chi Lai ${ }^{4}$ \\ 1 Instrument System and Chip Group, Department of Electric Engineering, National Cheng Kung University, \\ Tainan 70101, Taiwan; harukokashi@gmail.com (W.-J.M.); guosuicune@hotmail.com (S.-H.K.) \\ 2 Institute of Medical Science and Technology, National Sun Yat-sen University, Kaohsiung 80424, Taiwan \\ 3 Biotechnology and Biochemical Engineering Group, Department of Chemical Engineering, National Cheng \\ Kung University, Tainan 70101, Taiwan \\ 4 Department of Computer Science and Information Engineering, Nan Hua University, Chiayi 62249, Taiwan; \\ shivan0111@nhu.edu.tw \\ * Correspondence: robinluo@mail.ncku.edu.tw; Tel.: +886-6275-7575 (ext. 62375); Fax: +886-6236-6433
}

Academic Editor: Alexander Star

Received: 15 December 2015; Accepted: 30 March 2016; Published: 2 April 2016

\begin{abstract}
This paper presents a portable low-power battery-driven bioelectrochemical signal acquisition system for urea detection. The proposed design has several advantages, including high performance, low cost, low-power consumption, and high portability. A LT1789-1 low-supply-voltage instrumentation amplifier (IA) was used to measure and amplify the open-circuit potential (OCP) between the working and reference electrodes. An MSP430 micro-controller was programmed to process and transduce the signals to the custom-developed software by ZigBee RF module in wireless mode and UART in able mode. The immobilized urease sensor was prepared by embedding urease into the polymer (aniline-co-o-phenylenediamine) polymeric matrix and then coating/depositing it onto a MEMS-fabricated Au working electrode. The linear correlation established between the urea concentration and the potentiometric change is in the urea concentrations range of $3.16 \times 10^{-4}$ to $3.16 \times 10^{-2} \mathrm{M}$ with a sensitivity of $31.12 \mathrm{mV} / \log [\mathrm{M}]$ and a precision of $0.995\left(\mathrm{R}^{2}=0.995\right)$. This portable device not only detects urea concentrations, but can also operate continuously with a $3.7 \mathrm{~V}$ rechargeab-le lithium-ion battery $(500 \mathrm{~mA} \cdot \mathrm{h})$ for at least four days. Accordingly, its use is feasible and even promising for home-care applications.
\end{abstract}

Keywords: portable; battery-driven; bioelectrochemical signal acquisition; urea; potentiometric; immobilized urease; MEMS

\section{Introduction}

The urea concentration in human blood, called blood urea nitrogen (BUN), is significant for the assessment of normal renal function. BUN, a metabolic waste product of protein, is secreted by the kidneys and excreted from the body via urine. The BUN of a healthy adult ranges between 6 and $21 \mathrm{mg} / \mathrm{dL}(1-3.5 \mathrm{mM})$. Renal failure and related complications, such as acute or chronic urinary tract obstruction, hepatic failure and nephritic syndrome, could causes in urea concentration [1-4]. Currently, more than two thousand people per million worldwide rely on hemodialysis. Normally, hemodialysis is required when the urea concentration in serum is above $180 \mathrm{mg} / \mathrm{dL}$. BUN is temporarily raised in some diseases or human conditions such as liver dysfunction, upper gastro-intestinal bleeding, hydropenia, or hepatitis. Thus, it is essential to develop a device that can measure urea concentration rapidly and precisely. 
The urease catalytic reaction mechanism for urea is as follows:

$$
\mathrm{NH}_{2} \mathrm{CONH}_{2}+3 \mathrm{H}_{2} \mathrm{O}+\mathrm{H}^{+} \stackrel{\text { urease }}{\longrightarrow} \mathrm{HCO}_{3}^{-}+\mathrm{OH}^{-}+2 \mathrm{NH}_{4}^{+}
$$

According to Equation (1), the determination of urea concentration depends on the formation of ammonia or the change of $\mathrm{pH}$ [5]. In this manner, an electrochemical urea sensor can accurately measure the urea concentration.

A recent surge of research into bioelectrochemical sensors has concentrated on sensor fabrication via micro-electro-mechanical system (MEMS) technology. Many MEMS-based bioelectrochemical sensors for different applications have been described, such as E. coli bacteria detection [6], nitric oxide sensing [7], glucose detection [8], and DNA hybridization [9]. Each of these papers targeted the urea concentration via fabrication of a bioelectrochemical sensor by the MEMS technique.

In the past few decades, electrochemical sensors have been widely applied in various research fields owing to their high selectivity and sensitivity, rapid analysis, simplicity, easy fabrication and low cost $[10,11]$. These electrochemical sensors serve as transducers that convert a chemical concentration into an analog signal for measurement by an electronic device. Additionally, by physical entrapment and covalent bonding [12-18], urease has been immobilized onto a working electrode to achieve electropolymerization $[19,20]$. So far, all research efforts have been aimed at immobilizing urease within different kinds of polymeric matrices and with minimum leakage and loss of activity. To measure the urea concentration, various studies designed electrochemical urea sensors based on conductometry, potentiometry and amperometry with flow injection analysis (FIA). In recent years, much attention has been given to various urea biosensor designs, such as a solid-state urea biosensor [21] in the potentiometric mode, a gold interdigitated microelectrode urea biosensor based on polyhydroxybutyrate substrate in the impedimetric mode [22], and a carbon-black electrode urea sensor based on the amperometric mode [23-25]. Li et al. [26] developed a conducting polymer hydrogel amperometric biosensor for measuring human metabolites, such as uric acid, cholesterol and triglycerides, in a wide linear range. They reviewed the design and fabrication of such an electrode-Including different-dimensional nanostructures and biosensor applications $[27,28]$. More generally, these studies highlighted the importance of urea biosensors for bioelectrochemical sensing applications.

Recently, increasing attention has been devoted to research into personal health-care due to the globally aging population and chronic diseases. To meet the demands of personal health-care, the miniaturization of medical monitoring instruments into portable devices has become an important issue for health-care applications. Some commercial products based on the concept of point-of-care (home-care) service as well as long-term monitoring have already begun to appear on the market, such as portable and wearable blood glucose meters and continuous electrocardiogram (ECG) monitors [29-34]. In line with this trend, the main aim of the present study was to develop a rapid biomedical monitoring device.

Over the past few decades, much research has focused on portable biomedical devices that offer simple and reliable biomedical detection. In this regard, bioelectrochemical acquisition systems can acquire signals quickly and accurately. Some studies have used discrete components and evaluation board platforms to realize bioelectrochemical acquisition applications [35-39], while other works have concentrated on application-specific integrated circuit (ASIC) chips in single-, dual-, or multi-type electrochemical biosensor-integrated device studies [40-43]. In the present study, a bioelectrochemical acquisition system prototype device was realized as a biosensor for the kidney function. More specifically, the present paper proposes a bioelectrochemical monitoring prototype for the analysis of renal function by targeting urea concentration both in rapid detection and long-term monitoring. In this study, to increase the autonomy of users and improve the quality of detection, we focused on speed, convenience, performance and low-power consumption. Figure 1 schematically depicts our proposed bioelectrochemical acquisition prototype device for rapid analysis of renal function. As shown, it comprises a MEMS-based urea sensor, a front-end circuit, 
a signal-processing unit, an RS-232 driver, a ZigBee module, and custom-developed software for the monitoring. The proposed urea bioelectrochemical sensor based on a silicon substrate is fabricated by a MEMS technique and responds in the potentiometric mode. The proposed front-end circuit is linked to a 12-bit ADC, which converts the analog signal into a digital sequence. Furthermore, the microcontroller unit processes and transmits the data to a computer or any receiving device by two modes, namely a ZigBee RF module in wireless mode and a UART in cable mode. Finally, the custom-developed software features a user-friendly interface for data display and storage.
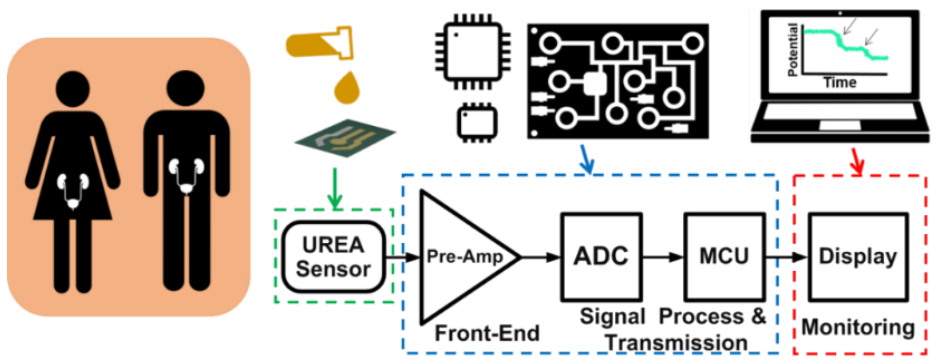

Figure 1. The proposed bioelectrochemical acquisition system prototype.

To sense urea, the bioelectrochemical module is composed of three electrodes: A Au working electrode, a Au counter electrode, and a $\mathrm{Ag} / \mathrm{AgCl}$ reference electrode. The gold and silver-based electrodes are manufactured by a MEMS process. The silver-based reference electrode is oxidized by an after-process treatment to form a $\mathrm{Ag} / \mathrm{AgCl}$ electrode, after which the immobilization of urease is performed by physical entrapment using electropolymerization.

The experimental results revealed that the system was able to achieve excellent performance in the calibration of urea concentration against potentiometric change. Accordingly, it would be suitable for application in rapid analysis and monitoring of renal function, for instance, in future development of a low-power wireless biotelemetry system-on-a-chip (SoC) device.

\section{Materials and Methods}

\subsection{Fabrication of the MEMS-Based Bioelectrochemical Sensor}

The proposed design of the electrochemical sensor for urea detection involved a three-electrode system fabricated by a MEMS technique. The electrochemical module consisted of three electrodes on a silicon substrate as the urea sensing area, comprising a Au working electrode, a Au counter electrode and a $\mathrm{Ag} / \mathrm{AgCl}$ reference electrode. The sensor's working electrode is the one that plays the principal role in urea sensing. Next, the counter electrode of the sensor was constructed from another gold electrode, while the reference electrode was a pseudo (quasi) Ag/ AgCl electrode [44,45]. The gold on the electrodes was deposited via e-beam evaporation, with the metallization utilized for interconnecting the metal traces and testing pads.

The fabrication process involved three steps: Standard photolithography, thin-film deposition and lift-off. A 4" phosphorus-doped silicon wafer (100) with a thickness of $500 \mu \mathrm{m}$ was used as the silicon substrate (Ultimate Materials Technology Co., Pingtung, Taiwan). The substrate was first cleaned using the standard RCA cleaning steps. Afterwards, a low-stress $1.0 \mu \mathrm{m}$-thick $\mathrm{Si}_{3} \mathrm{~N}_{4}$ layer was deposited on the silicon substrate as the isolation layer on each side via a low-pressure chemical vapor deposition system (LPCVD) (NFC-NCTU, Hsinchu, Taiwan). The operation conditions to deposit the low-stress $\mathrm{Si}_{3} \mathrm{~N}_{4}$ thin film were: $\mathrm{SiH}_{2} \mathrm{Cl}_{2}(85 \mathrm{sccm}), \mathrm{NH}_{3}(175 \mathrm{sccm}), 50 \mathrm{mtorr}$ pressure, and a temperature of $850{ }^{\circ} \mathrm{C}$.

The first step in fabricating the three-electrode layer from the MEMS process involved spin-coating the AZ1500 photoresist with a thickness of 1.5 ctrode layer from the MEMS proces $3 \mathrm{~N}_{4}$ ), and then setting the pattern with a Mask Aligner (MA 150CC, SUSS Micro-Tec, Garching, Germany). Then, a Ti (15 nm) 
layer was deposited to enhance the adhesion of Au to the silicon surface, after which e-beam evaporation was used to deposit the Au layer $(120 \mathrm{~nm})$. The pattern on the Au layer was then created by a standard lift-off process. In this manner, both the Au electrodes namely the working and counter electrodes were fabricated. Also the fabrication of the Ag electrode $(120 \mathrm{~nm})$ followed the above-mentioned process. The metal-deposition conditions are summarized in Table 1, with each layer deposited in two steps. The metal-deposition rate of the first step was 10 times slower than that of the second step. However, the two-step metal-deposition procedure was used because it gave superior adhesion and film quality. After finishing the micro-fabrication of the three electrodes, the Ag electrode was oxidized in a $\mathrm{FeCl}_{3}(100 \mathrm{mM})$ solution to produce the $\mathrm{Ag} / \mathrm{AgCl}$ reference electrode. Finally, the fabrication process was completed by washing the three electrodes in distilled water. A flow chart of the entire process is shown in Figure 2.

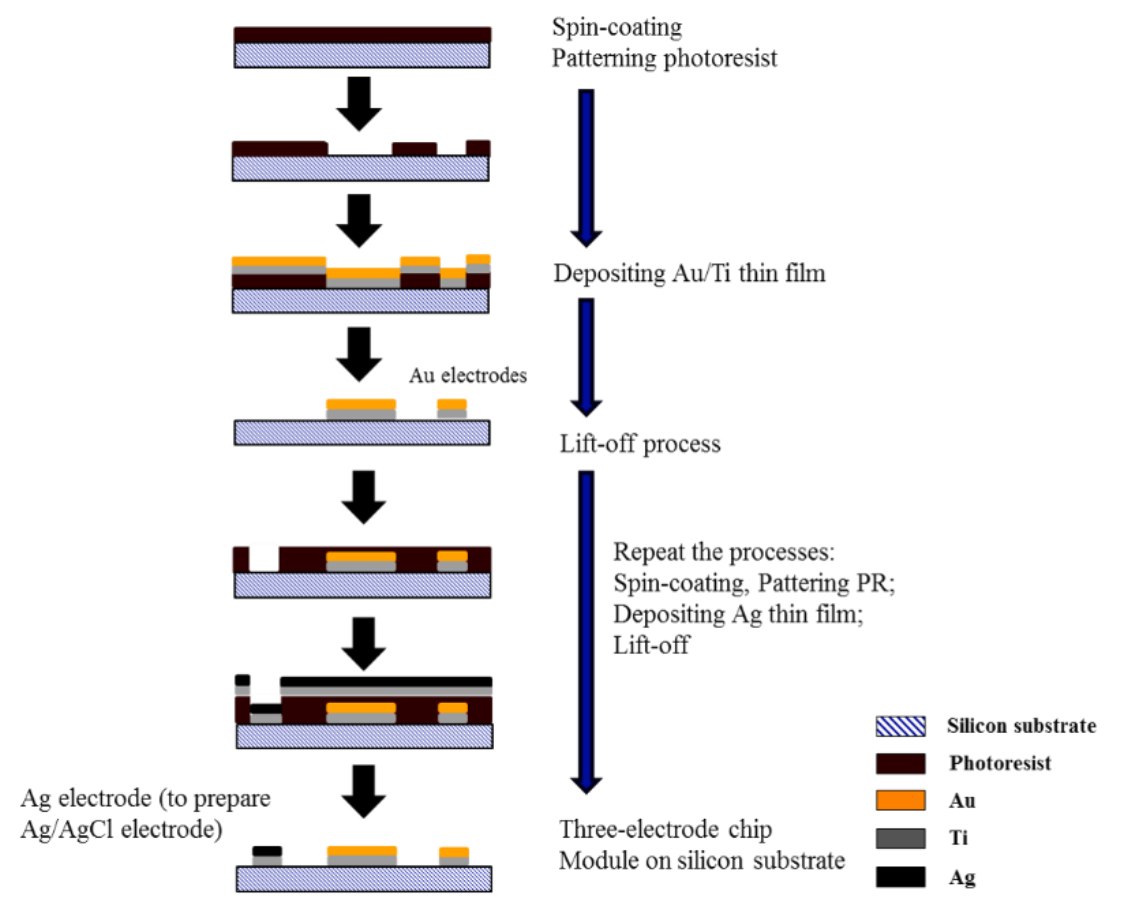

Figure 2. Three-electrode chip molding process flow.

Table 1. Deposition conditions of metal layers ( $\mathrm{Ti}, \mathrm{Au}$ and $\mathrm{Ag}$ ) on the substrate.

\begin{tabular}{cccc}
\hline & $\mathbf{T i}$ & $\mathbf{A u}$ & $\mathbf{A g}$ \\
\hline 1st Deposition rate & $0.01 \mathrm{~nm} / \mathrm{s}$ & $0.01 \mathrm{~nm} / \mathrm{s}$ & $0.01 \mathrm{~nm} / \mathrm{s}$ \\
1st Thickness & $5 \mathrm{~nm}$ & $5 \mathrm{~nm}$ & $5 \mathrm{~nm}$ \\
2nd Deposition rate & $0.1 \mathrm{~nm} / \mathrm{s}$ & $0.1 \mathrm{~nm} / \mathrm{s}$ & $0.1 \mathrm{~nm} / \mathrm{s}$ \\
2nd Thickness & $10 \mathrm{~nm}$ & $115 \mathrm{~nm}$ & $115 \mathrm{~nm}$ \\
Vacuum & & $3 \times 10^{-6}$ torr & \\
\hline
\end{tabular}

\subsection{Electrochemical Detection of Urea Concentration}

The potentiometric mode was used to detect the urea concentration. Three electrodes, namely the working, counter and reference electrodes, were needed to perform the electropolymerization. The conductive materials not only enhanced the conductivity of the electrodes, but also trapped the urease enzyme which detected the urea. Cyclic voltammetry was used to trigger the electropolymerization for the formation of the conductive polymeric matrix on the $\mathrm{Au}$ working electrode. 
By physical entrapment, urease (E.C. 3.5.1.5, from Jack Beans, Type III, Sigma-Aldrich Inc., St. Louis, MO, USA, crude enzyme without further purification or pretreatment before use) in a concentration of $5.0 \mathrm{mg} / \mathrm{mL}$ was immobilized within the conductive polymeric matrix. Furthermore, urease was mixed with aniline (ANI) monomer (Sigma-Aldrich Chemie GmbH, Buchs, Switzerland) and o-phenylenediamine (o-PD; Sigma-Aldrich Chemie $\mathrm{GmbH}$ ), after which cyclic voltammetric polymerization was initialized for the synthesis of poly(ANI-co-o-PD), the polymer, poly(aniline-co-o-phenylenediamine) as well as for the immobilization of urease. Polyaniline is a well-known electroconducting polymer in a linear chain. However, it is difficult to firmly entrap urease only by polyaniline. Therefore, $o$-phenylenediamine was used to add a branching structure into the polymer matrix for enhancing the immobilization of urease. The scan range was from -0.2 to $1.0 \mathrm{~V}$, with a scan rate of $50 \mathrm{mV} / \mathrm{s}$ over 10 cycles (i.e., 20 segments). To detect the urea concentration, urease catalyzed the reaction of urea into ammonia, as shown in formula (1), so that a corresponding potential-change signal was obtained. Instead of the three-electrode system, only the working and reference electrodes (a two-electrode process) were needed to detect the urea concentration. The open-circuit potential (OCP) between the working and reference electrodes was measured and correlation of the urea concentration was established based on the Nernst equation.

\subsection{Low-Power Battery-Driven Bioelectrochemical Acquisition System}

The block diagram of the battery-driven portable potentiometric device designed in this work is shown in Figure 3. The open-circuit potential (OCP) obtained from the sensing electrode (i.e., the polymer immobilized urea on the MEMS-base substrate) was amplified and filtered by the front-end circuit, which included an instrumentation amplifier and a low-pass filter. The low-pass filter was composed of an operation amplifier and passive components. Next, the analog signals were converted and processed by a commercial MCU, which included a 12-bit ADC. Afterwards, the digital signals were transmitted to a laptop computer by RS-232 serial communication protocol (MAX3232E-Q1, Texas Instruments Inc., Dallas, TX, USA) in cable mode, or an IEEE 802.15.4/ZigBee-compliant transceiver in wireless mode. Finally, the data were further plotted and stored by the custom-developed software.

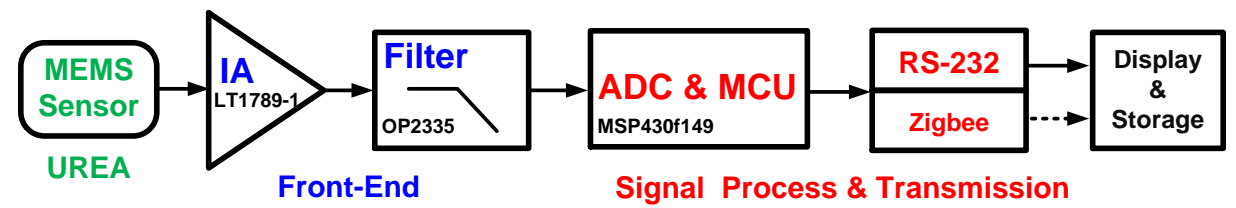

Figure 3. Block diagram of the proposed bio-electrochemical acquisition system.

\subsection{Bioelectrochemical Readout Circuit}

Herein, the urea detection was mainly aimed at potential responses between the electrochemical cell working electrode (WE) and the reference electrode (RE). The potential response of the proposed urea sensor is called the open-circuit potential, which involves no current flow through the WE and RE during the experiments; accordingly, the input impedance of the terminals connected to the WE and RE must be as high as possible. In addition, the electrochemical cell WE and RE of the urea sensor were linked to the proposed bioelectrochemical readout circuit for the bioelectrochemical signal acquisition.

Figure 4 schematically depicts the proposed readout circuit, which includes two parts: The front-end amplifier and low-pass filter. The front-end amplifier of the readout circuit must possess the following characteristics: a high common mode rejection ratio (CMRR), high input impedance, low-power consumption, and low noise for processing the bioelectrochemical signals. Therefore, a high-performance instrumentation amplifier (LT1789-1, Linear Technology, Milpitas, CA, USA) was adopted as the front-end readout circuit of the system. The utilized amplifier had a CMRR of $100 \mathrm{~dB}$ and a power supply rejection ratio (PSRR) of $100 \mathrm{~dB}$. The WE and RE were connected to 
the differential inputs of the instrumentation amplifier, with $\mathrm{R}_{\mathrm{G}}$ used to tune the gain for the readout potential change of the urea concentration. Accordingly, the gain of LT1789-1 can be represented as:

$$
\text { Gain }=\left[1+\left(\frac{200 k \Omega}{R_{G}}\right)\right]
$$

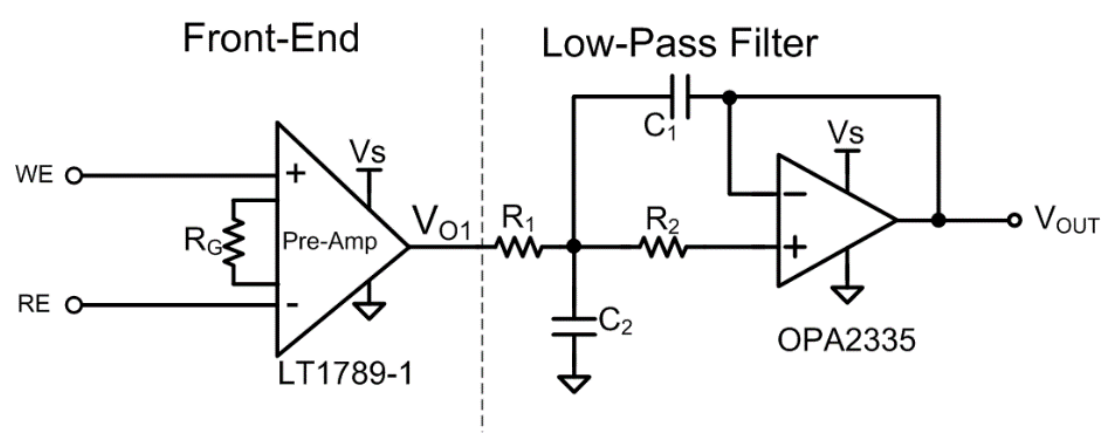

Figure 4. The proposed bio-electrochemical readout circuit for OCP measurement.

Following the instrumentation amplifier circuit, a low-pass filter with a low cut-off frequency was selected to suppress the out-of-band noise and to provide better a signal-to-noise ratio (SNR). In addition, the low-pass filter was designed with an operational amplifier (OPA2335, Texas Instruments Inc., Dallas, TX, USA) to reduce the high frequency noise.

The gain of this instrumentation amplifier has the advantage that it can be tuned for various bioelectrochemical experiments by trimming the resistor value and the bandwidth of the filters can be designed to suit the system. The output of the readout circuit was connected to the input of the MSP430f149 ADC (Texas Instruments Inc., Dallas, TX, USA) for data processing and the UART unit for data transmission.

The LT1789-1 features low-power consumption, a high CMRR, high PSRR, high accuracy, rail-to-rail input and output range, and a wide supply voltage (2.2-36 V). Considering the purpose of the portable low-power system, the instrumentation amplifier (LT1789-1) was designed for low-voltage supply operation with a quiescent current of $95 \mu \mathrm{A}$.

\subsection{Microcontrol Unit Usage}

The proposed peripheral devices included an ADC and an MCU. Therefore, an ultra-low-power high-performance 16-bit RISC microcontroller (MSP430f149, Texas Instruments Inc., Dallas, TX, USA) with a 12-bit built-in ADC was selected for the system [46]. This integrates 2 KB of SRAM, and $48 \mathrm{~KB}+256$ bytes of flash memory for code programing. As mentioned above, the microcontroller featured a powerful 16-bit RISC CPU, 16-bit registers and constant generators that allow maximum code efficiency. Since the resolution of the built-in ADC is 12 bits, it is suitable for biomedical instruments and biophysical measurements.

The bioelectrochemical analog signals extracted by the analog front-end circuit are converted into digital data by the built-in ADC. Next, the MCU processes the digital signals and sends them to the computer for data display and storage via the UART or radio frequency module. The personal computer then acquires the signals through the peripheral devices and processes them using the custom-develop software.

The architecture of the commercial low-power MSP430f149 MCU consists of two built-in 16-bit timers, a 12-bit ADC, two UARTs, 48 I/O pins and small size and weight. In addition, it has one active mode and five software selectable power-saving modes; thus, it is optimized to achieve an extended battery life for portable measurement applications. In power-saving mode, the digitally controlled oscillator (DSC) can wake up from a low-power mode to active mode in less than $6 \mu$ s, including 
performing the functions of power-management control, enabling instrumentation amplifier, ADC and processing the signals. Furthermore, under the active mode, the active current is $280 \mu \mathrm{A}$ at $1 \mathrm{MHz}$, while the idle current is $1.6 \mu \mathrm{A}$ in standby mode.

\subsection{Peripheral Device for Signal Monitoring and Storage}

The UART interface is widely used for serial communication and its transport protocol is simpler than that of the universal serial bus (USB). Although UART has relatively slow data transmission, it is sufficient for this work due to the long response time of the sensors.

The peripheral devices of the proposed system transmit the acquired bioelectrochemical signal to the computer for data display and storage. In front of the peripheral device, the MCU processes and sends the signals via a UART or wireless transmission solution. Furthermore, a personal computer or laptop computer acquires the signals through the peripheral devices and displays them by using system designed software. The present study employed two modes of data transmission for the proposed data acquisition, as described below.

In cable mode, the selected MSP430f149 MCU has two UART interfaces; thus, the proposed portable device can be connected to a computer via a USB, a UART port and/or a RS-232 serial protocol. A multi-channel RS-232 line driver/receiver (MAX3232E-Q1, Texas Instruments Inc. Texas Instruments Inc., Dallas, TX, USA) was used to meet the requirements of TIA/EIA-232-F (RS-232) and to provide the electrical interface between the asynchronous communication controller and the serial-port connector.

In wireless mode, the chosen wireless module was an IEEE 802.15.4/ZigBee-compliant transceiver. It contains a powerful 8-bit $8051 \mathrm{MCU}$ and an RF single-chip (CC2530, Texas Instruments Inc., Dallas, TX, USA) 2.4 GHz IEEE 802.15.4-compliant RF transceiver. The RF transceiver module is employed as a communication transceiver in bidirectional telemetric devices. Accordingly, a wireless sensor network can be built from the transceiver modules for various applications. The transmission range of the transceiver is $100 \mathrm{~m}$ (LOS). Additionally, the receiver unit receives UART formatted data transmitted via a USB port on a UART/USB interface IC (FT232RL, FTDI Chip Inc., Glasgow, Scotland).

The proposed custom-developed software was written in Visual Basic and Lab-View to provide a user-friendly interface to display the data in real-time and to automatically upload the data to a database via the Internet.

\section{Results and Discussions}

\subsection{Urea Disposable Sensing Microchip}

A three-electrode system functioning as a urea sensor, as well as a system for detecting urea concentration, was fabricated by a MEMS technique. A schematic diagram of the fabricated three microelectrode urea sensor prototype is shown in Figure 5a. As can be seen, the diameter of the sensing area is $2.4 \mathrm{~mm}$, while those of the counter and reference electrodes are both $1.0 \mathrm{~mm}$. The total area of the urea sensor is $70 \mathrm{~mm}^{2}$, with an actual sensing area of $4.78 \mathrm{~mm}^{2}$ on the working electrode. Additionally, polydimethylsiloxane (PDMS) was used to create a reservoir for the urea samples. Detection of the urea concentration was carried out once the urease enzyme was immobilized on the Au working electrode via the formation of a film of copolymer poly(ANI-co-o-PD), i.e., poly(aniline-co-o-phenylenediamine) (i.e., A photograph of the fabricated three-electrode electropolymerization urea sensing chip is presented in Figure 5b, with the proposed sensor integrated with the IC heterogeneously. Therefore, the proposed sensor was attached to a printed circuit board (PCB) and the reservoir channel holding the working electrode was made by PDMS, as shown in Figure 5c. 


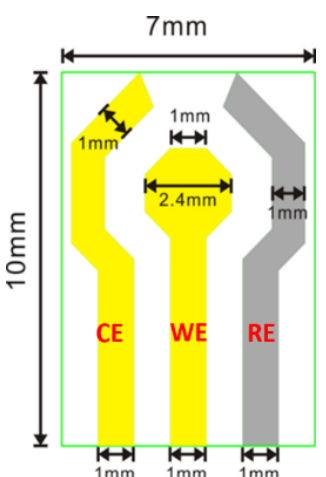

(a)

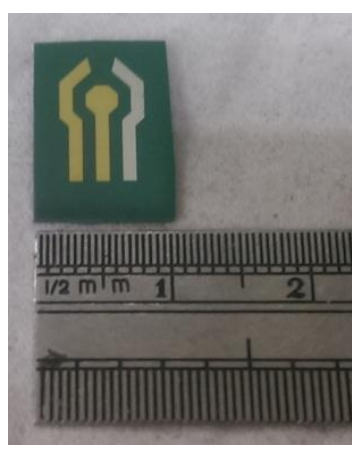

(b)
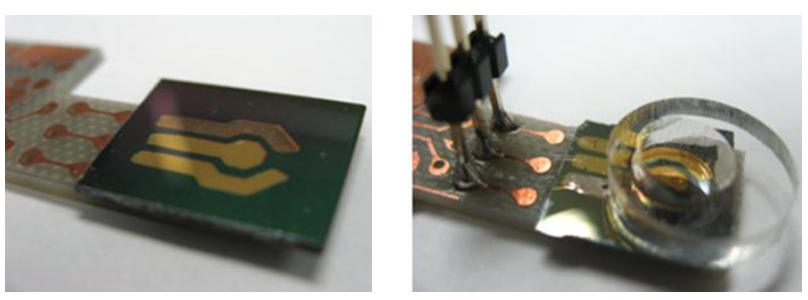

(c)

Figure 5. (a) Schematic diagram of the proposed urea sensor chip; (b) Photo of the urea sensor; (c) Photos of the disposable urea sensor integrated with the PCB (Left) and PDMS (Right).

\subsection{SEM Images of the Poly Film Fabricated on the Au Electrode}

The chemical structure of poly(ANI-co-o-PD) is shown in Figure 6. Polyaniline can only provide electro-conductivity; however, it has a linear chain structure. Therefore, we used o-phenylenediamine to graft with aniline so that the copolymer thus fabricated could more firmly entrap urease. Figure 7a-c present the SEM images of the Au surface, the morphology of polyaniline and the morphology of the poly(ANI-co-o-PD) adhered onto Au, respectively. Obviously, the presence of $o$-phenylenediamine together with aniline, after electropolymerization, formed a kind of network structure, which could be seen on the surface of the copolymer film thus created, which then enhanced the immobilization effect of urease onto the electrode.

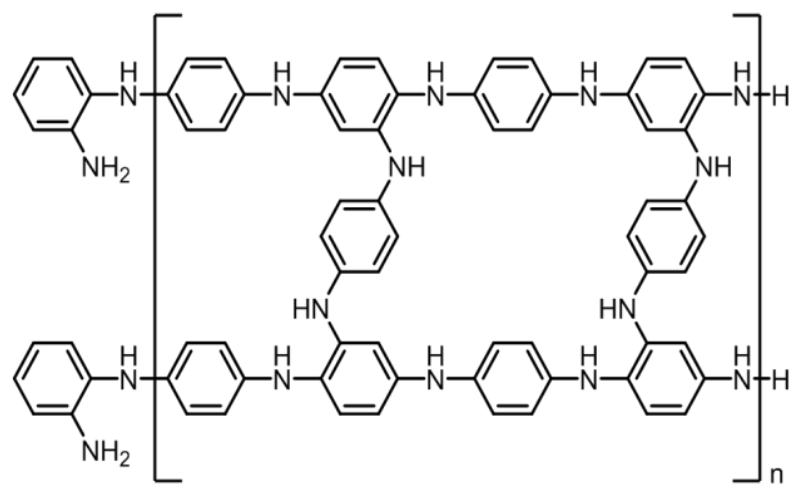

Figure 6. The chemical structure of poly(aniline-co-o-phenylenediamine).
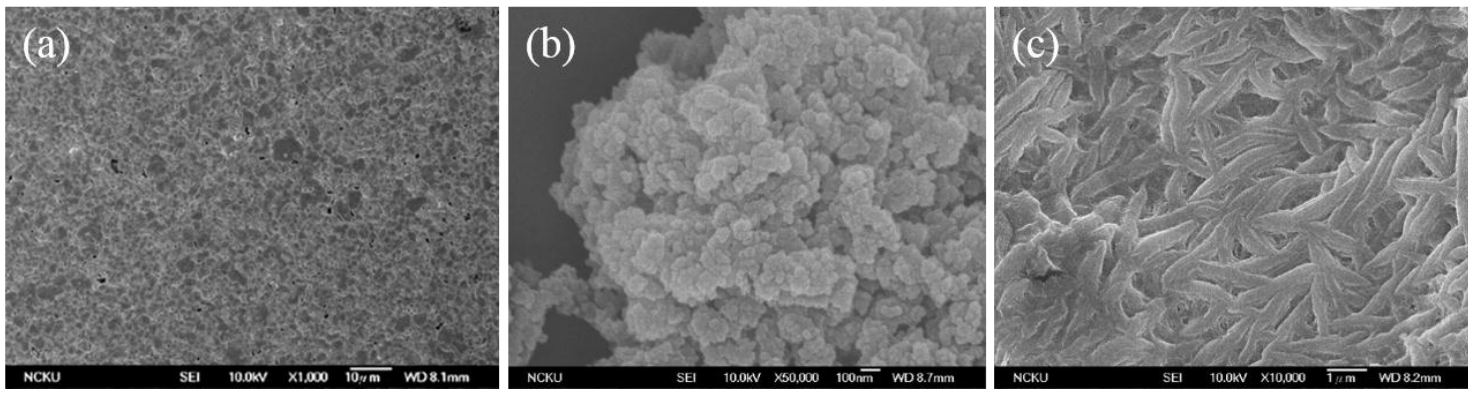

Figure 7. SEM images of the sensing surface of (a) $\mathrm{Au}$; (b) polyaniline electro-fabricated onto $\mathrm{Au}$; and (c) poly (aniline-co-o-phenylenediamine) on Au. 


\subsection{The Proposed Bioelectrochemical Signal Acquisition System}

Portable biomedical instruments for the purpose of home-care application are becoming increasingly important. The proposed acquisition system presented in this paper was implemented and integrated with a MEMS urea sensor, a low-power bioelectrochemical readout circuit, an ultra-low-power MCU, a low-power RS-232 driver/receiver, and custom-developed software, with the entire system shown in Figure 8 . The size of the proposed system device is $6.0 \times 4.3 \mathrm{~cm}^{2}$ and the height is approximately $2 \mathrm{~cm}$.

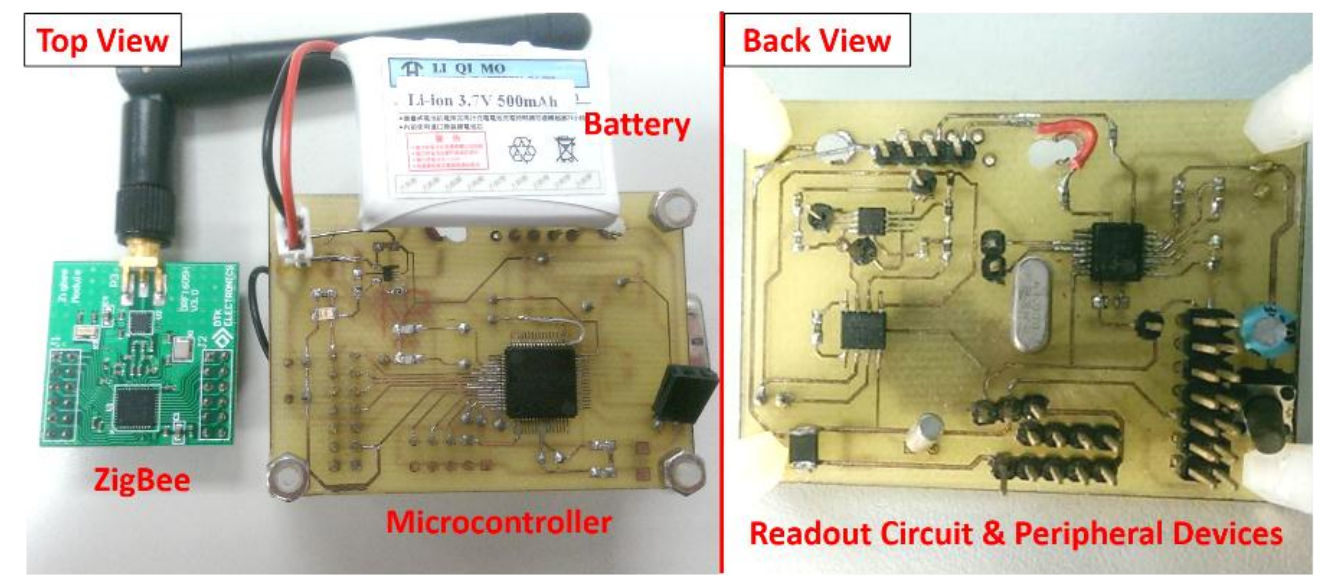

Figure 8. Realization of the proposed system device.

The proposed device and sensor for urea concentration detection are described in the following. First, the working and reference electrodes of the urea sensor were connected to the dual inputs of the readout circuit, and the open-circuit potential between them was measured; then, the potential signal from the sensor was amplified and linked to the ADC for signal conversion. The gain was set to $40 \mathrm{~dB}$ for this active component. The chosen MCU was programmed to initialize the built-in ADC, clock system and UART. The reference voltage provided for the built-in ADC and sampling timer was $3.3 \mathrm{~V}$. In addition, the sampling timer (SHT_0) and the sampling time $\left(t_{\text {sample }}=4 \cdot t_{\mathrm{ADC12CLK}} \cdot 8\right)$ were chosen for signal processing. The MCU clock was produced by an external $4 \mathrm{MHz}$ crystal oscillator. The baud rate of the UART was $9600 \mathrm{bps}$ and in cable mode, the peripheral device included an MCU and UART/RS232 communication chip (MAX3232E-Q1). The MCU obtains biomedical analog signals by using the proposed processing chip and transmits the signals via UART to the PC. Furthermore, in wireless mode, the device contains a MCU and wireless ZigBee module (CC2530); accordingly, the MCU can transmit biomedical signals wirelessly.

The factors of long-term monitoring, low-power consumption, low cost, and compact size must be taken into consideration. In cable mode, the total power consumption of the proposed design is $12.42 \mathrm{~mW}$ with a supply voltage of $3.3 \mathrm{~V}$. Consequently, the power dissipation of the proposed system device is considered a low-power design and therefore suitable for battery-driven operation and long-term monitoring. The MCU can transmit the biomedical signals wirelessly with a power dissipation of $32.62 \mathrm{~mW}$. A wireless solution is more appropriate for portable monitoring applications, despite consuming more power. Moreover, this system is very stable and can be continuously operated for at least 4 days with a $500 \mathrm{~mA} \cdot \mathrm{h}$ battery in cable mode; by contrast, the device lifetime in wireless mode is about 2 days. Table 2 summarizes the power consumption of the proposed readout system device in dual mode. 
Table 2. Power consumption of the proposed readout system device in dual mode.

\begin{tabular}{ccccc}
\hline Cable Mode & Front-End & MCU & MAX3232 & Regulator \\
\hline P.C. $(\mathrm{mW})$ & 0.32 & 7.88 & 3.31 & 0.92 \\
\% of Total P.C. & $2.57 \%$ & $63.40 \%$ & $26.63 \%$ & $7.40 \%$ \\
Total Power & \multicolumn{5}{c}{$12.43 \mathrm{~mW}$} \\
Device lifetime & \multicolumn{4}{c}{$4-5$ days (A 3.7V Li-ion $500 \mathrm{~mA} \cdot \mathrm{h}$ battery) } \\
Wireless mode & Front-end & MCU & ZigBee & Regulator \\
P.C. $(\mathrm{mW})$ & 0.32 & 7.88 & 23.5 & 0.92 \\
\% of Total P.C. & 0.98 & $24.15 \%$ & $72.04 \%$ & $2.82 \%$ \\
Total Power & \multicolumn{4}{c}{$32.62 \mathrm{~mW}$} \\
Device lifetime & \multicolumn{5}{c}{ 1-2 days (A 3.7V Li-ion 500 mA.h battery) } \\
\hline
\end{tabular}

The proposed battery-driven device is powered by a $3.3 \mathrm{~V}$ regulated external power supply. Therefore, the power supply of this device consisted of a $+3.3 \mathrm{~V}$ voltage regulator commercial IC, TPS76933 and bulk decoupling capacitors. The TPS769 family is a low-dropout-voltage and low-noise regulator; accordingly, it is suitable for portable applications. The TPS769 also features a logic-enabled sleep mode to shut down the regulator, thereby reducing quiescent current to $1 \mu \mathrm{A}$, which makes the IC appropriate for use in battery-powered devices. A rechargeable $3.7 \mathrm{~V} \mathrm{Li-ion} 500 \mathrm{~mA} \cdot \mathrm{h}$ battery pack provided the power to the proposed battery-driven device.

\subsection{Detection of Urea Concentration by the Proposed System Device and Sensor}

In this paper, electrochemical analysis experiments were conducted with the proposed system device and urea electrochemical sensor. The urea concentration measurement was performed by the sequential injection of urea up to a working volume of $50 \mu \mathrm{L}$. The urea concentration of the proposed system device was calibrated by using a commercial potentiostat (CHI-611C, CH Instruments Inc., Tennison Hill Drive Austin, TX, USA) as the standard. Figure 9 shows the time profile of the corresponding voltage changes in response to the sequential injections of urea. Figure 10 shows the potential variations against the urea concentrations obtained. The minimum urea concentration required that could be detected was experimentally found to be $3.16 \times 10^{-4} \mathrm{M}(1.89 \mathrm{mg} / \mathrm{dL})$ with the $\mathrm{pH}$ set at 7.4. Furthermore, a sensitivity of $31.12 \mathrm{mV} / \log [\mathrm{M}]$ could be achieved in the urea concentration range of $3.16 \times 10^{-4} \mathrm{M}$ to $3.16 \times 10^{-2} \mathrm{M}(1.89-189.93 \mathrm{mg} / \mathrm{dL})$ with a precision of 0.995 $\left(R^{2}=0.995\right)$. With a sample volume of only $10 \mu \mathrm{L}$, accurate measurement of the urea concentration could be obtained in less than $100 \mathrm{~s}$.

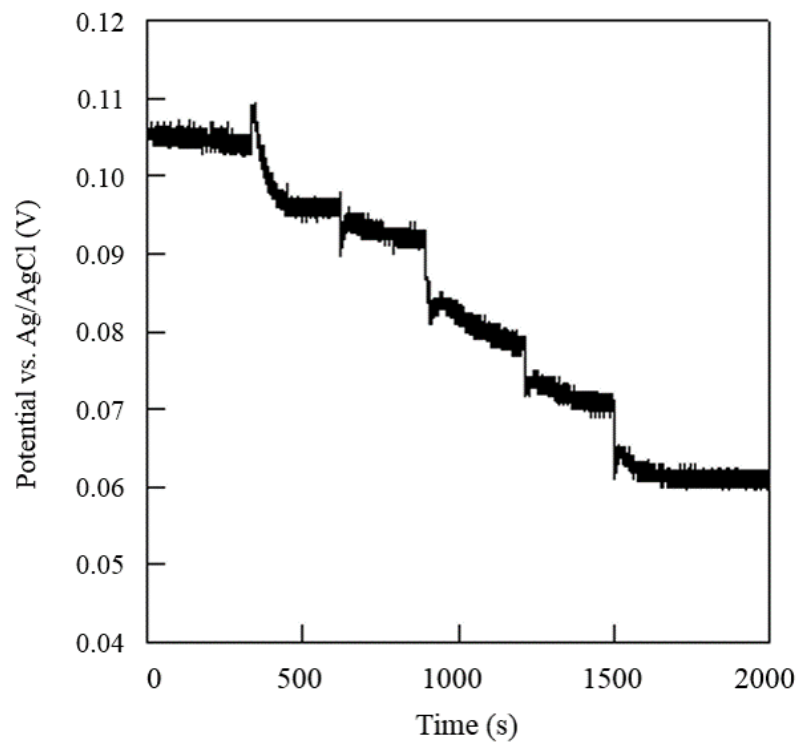

Figure 9. Potential time profile in response to the injection of urea solution. 


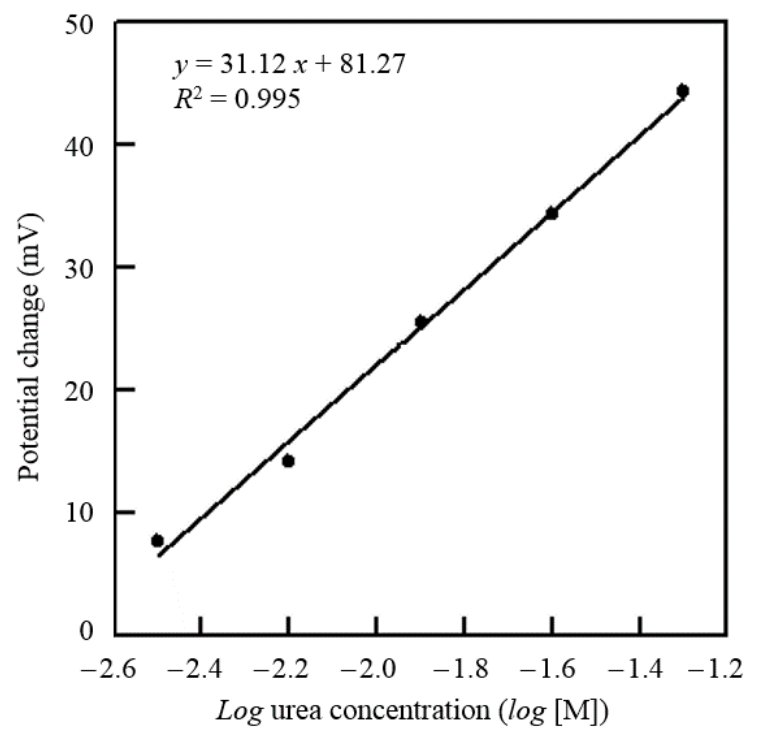

Figure 10. Characteristic curve of urea concentration in test samples.

According to the Nernst equation, the sensing results can be reasonably explained. Moreover, the results confirm the successful measurement of urea concentrations by this portable device. We further compared the sensing results in this work with our previous work [47]. The major differences are listed as follows. First, the proposed battery-driven portable device in the present study replaces the function of a potentiostat, while in our previous work the sensing system was operated by a potentiostat. Second, the MEMS in our previous work was designed with a microchannel for the pumping of microfluid to the sensing area, while in the present work the MEMS has no pumping action. A comparison of the sensing performance for the present work and our previous work is listed in Table 3. With an injection volume of $10 \mu \mathrm{L}$ to a working volume of $50 \mu \mathrm{L}$ whole serum, the linear calibration had a sensitivity of $1.59 \pm 0.47 \mathrm{mV} / \log [\mathrm{M}]$ for serum urea concentration, which was similar to [47]. The experimental results of the integrated device and sensor are summarized in Table 4, while Table 5 compares the differences between the system proposed in the present work and the design described by Wang et al. [40].

Table 3. Comparison between the proposed sensor and previous work.

\begin{tabular}{ccccc}
\hline Specification & \multicolumn{2}{c}{ [47] } & \multicolumn{2}{c}{ This Work } \\
\hline Background Solvent & water & serum & water & serum \\
Sensitivity (mV/log [M]) & $28.68 \pm 0.01$ & $2.71 \pm 0.56$ & 31.12 & $1.59 \pm 0.47$ \\
Sampling Time (s) & 400 & 400 & 100 & 100 \\
Response Time (s) & $\sim 800$ & $\sim 1200$ & $\sim 100$ & $\sim 500$ \\
Sample Volume (mL) & 0.20 & 0.20 & 0.01 & 0.01 \\
Working Volume $(\mathrm{mL})$ & 5 & 5 & 0.05 & 0.05 \\
\hline
\end{tabular}

Table 4. Specifications results of the proposed system and sensor.

\begin{tabular}{|c|c|c|}
\hline Key Item & \multicolumn{2}{|c|}{ Specification } \\
\hline System Power Supply & \multicolumn{2}{|c|}{$3.3 \mathrm{~V}$} \\
\hline Power Consumption & Cable & ZigBee \\
\hline (Cable mode \& Wireless mode) & $12.42 \mathrm{~mW}$ & $32.62 \mathrm{~mW}$ \\
\hline Linearity $\left(R^{2}\right)$ & \multicolumn{2}{|c|}{0.995} \\
\hline Sensitivity (mV / log [M]) & \multicolumn{2}{|c|}{31.12} \\
\hline UART Baud rate & \multicolumn{2}{|c|}{9600} \\
\hline Device Size & \multicolumn{2}{|c|}{$6.0 \times 4.3 \mathrm{~cm}^{2}$} \\
\hline Sensor Size & \multicolumn{2}{|c|}{$0.7 \times 1.0 \mathrm{~cm}^{2}$} \\
\hline
\end{tabular}


Table 5. Comparison between our system and previous work.

\begin{tabular}{ccc}
\hline Specification & {$[40]$} & This Work \\
\hline Circuit Composition & CMOS/FPGA & Commercial Chip \\
Power Supply & $1.8 \mathrm{~V} / 3.3 \mathrm{~V}$ & $3.3 \mathrm{~V}$ \\
Linearity & 0.998 & 0.995 \\
Power consumption & $157.25 \mathrm{~mW}$ & $32.62 \mathrm{~mW}$ \\
Data transmission & $433 \mathrm{MHz} / \mathrm{ISM}$ & $2.4 \mathrm{GHz} /$ ZigBee \\
\hline
\end{tabular}

\section{Conclusions}

To achieve the requirements of low-power consumption, high portability, and low cost, we proposed a low-power battery-driven portable device in this paper. The performance of this device was successfully confirmed via its integration with a disposable urea sensor. The proposed system device includes the following modules: A low-supply-voltage IA, 2nd-order low-pass filter, low-power microcontroller, a RS-232 driver/receiver, an IEEE 802.15.4/ZigBee-compliant transceiver and custom-developed software. The potential response results of the urea sensor show that the sensitivity is $31.12 \mathrm{mV} / \log [\mathrm{M}]$, which was achieved in the urea concentration range of $3.16 \times 10^{-4} \mathrm{M}$ to $3.16 \times 10^{-2} \mathrm{M}(1.89-189.93 \mathrm{mg} / \mathrm{dL})$. This low-power portable device can not only quantify the urea concentration, but also stably measure urea signals for at least four days running on a 3.7-V Li-ion battery. Consequently, this low-power portable device holds potential and its use in biosensors for home health care applications is feasible.

Acknowledgments: The authors gratefully acknowledge the financial support on this work by Ministry of Science and Technology (MOST) of Taiwan, under grant number MOST 104-2218-E-006-022. The effort contributed by Yu-Sung Chang (both are Master graduates from Chemical Engineering, National Cheng Kung University) in the initial stage of this work were also acknowledged. We also appreciate National Nano Device Laboratories (NDL) and Center for Micro/Nano Science and Technology (CMNST) for providing all apparatus and resources of the MEMS process.

Author Contributions: W.J. Ma carried out the fabrication of the circuit device and participation of the cross-field experiment. S.H. Kuo carried out the fabrication of MEMS material experiments. J.L. Lin carried out the fabrication of sensing material experiments and SEM images. S.H. Chou carried out extra experiments to verify and provided to the reviewer. P.H. Chen carried out the urea concentration calibration experiments. M.J. Syu designed and assigned the experiments, discussed the data. S.C. Lai assigned the digital part of the system experiment. C.H. Luo assigned the system and discuss MEMS material experiment. W.J. Ma collected the experiment data and wrote the paper. S.C. Lai, M.J. Syu and C.H. Luo supervised the research, critically reviewed and revised the paper.

Conflicts of Interest: The authors declare no conflict of interest.

\section{References}

1. Aronson, D.; Mittleman, M.A.; Burger, A.J. Elevated blood urea nitrogen level as a predictor of mortality in patients admitted for decompensated heart failure. Am. J. Med. 2004, 116, 466-473. [CrossRef] [PubMed]

2. Ronco, C.; Bellomo, R.; Homel, P.; Brendolan, A.; Dan, M.; Piccinni, P.; Greca, G.L. Effect of different doses in continuous veno-venous hemofiltration on outcomes of acute renal failure: A prospective randomized trial. Lancet 2000, 356, 26-30. [CrossRef]

3. Tiwari, A. A novel nanocomposite matrix based on silylated chitosan and multiwall carbon nanotubes for the immobilization of urease. J. Inorg. Organomet. Polym. Mater. 2009, 19, 361-366. [CrossRef]

4. Bozgeyik, I.; Senel, M.; Cevik, E.; Abasıyanık, M.F. A novel thin film amperometric urea biosensor based on urease-immobilized on poly ( $N$-glycidylpyrrole-co-pyrrole). Curr. Appl. Phys. 2011, 11, 1083-1088. [CrossRef]

5. Ho, W.O.; Krause, S.; McNeil, C.J.; Pritchard, J.A.; Armstrong, R.D.; Athey, D.; Rawson, K. Electrochemical Sensor for Measurement of Urea and Creatinine in Serum Based on ac Impedance Measurement of Enzyme-Catalyzed Polymer Transformation. Anal. Chem. 1999, 71, 1940-1946. [CrossRef] [PubMed]

6. Gau, J.J.; Lan, E.H.; Dunn, B.; Ho, C.M.; Woo, J.C.S. A MEMS based amperometric detector for E. coli bacteria using self-assembled monolayers. Biosens. Bioelectron. 2001, 16, 745-755. [CrossRef] 
7. Chang, C.W.; Maduraiveeran, G.; Xu, J.C.; Hunter, G.W.; Dutta, P.K. Design, fabrication, and testing of MEMS-based miniaturized potentiometric nitric oxide sensors. Sens. Actuators B Chem. 2014, 204, 183-189. [CrossRef]

8. Kudo, H.; Sawada, T.; Kazawa, E.; Yoshida, H.; Iwasaki, Y.; Mitsubayashi, K. A Flexible and wearable glucose sensor based on functional polymers with Soft-MEMS techniques. Biosens. Bioelectron. 2006, 22, 558-562. [CrossRef] [PubMed]

9. Cha, J.; Han, J.I.; Choi, Y.; Yoon, D.S.; Oh, K.W. DNA hybridization electrochemical sensor using conducting polymer. Biosens. Bioelectron. 2003, 18, 1241-1247. [CrossRef]

10. Eggenstein, C.; Borchardt, M.; Diekmann, C.; Gründig, B.; Dumschat, C.; Cammann, K.; Knoll, M.; Spener, F. A disposable biosensor for urea determination in blood based on an ammonium-sensitive transducer. Biosens. Bioelectron. 1999, 14, 33-41. [CrossRef]

11. Yin, L.T.; Lin, Y.T.; Leu, Y.C.; Hu, C.Y. Enzyme immobilization on nitrocellulose film for pH-EGFET type biosensors. Sens. Actuators B Chem. 2010, 148, 207-213. [CrossRef]

12. Senillou, A.; Jaffrezic-Renault, N.; Martelet, C.; Cosnier, S. A miniaturized urea sensor based on the integration of both ammonium based urea enzyme field effect transistor and a reference field effect transistor in a single chip. Talanta 1999, 50, 219-226. [CrossRef]

13. Koncki, R.; Radomska, A.; Gląb, S. Potentiometric determination of dialysate urea nitrogen. Talanta 2000, 52, 13-17. [CrossRef]

14. Jin, J.H.; Pake, S.H.; Lee, C.W.; Min, N.K.; Hong, S.I. Fabrication of amperometric urea sensor based on nano-porous silicon technology. J. Korean Phys. Soc. 2003, 42, S735-S738.

15. Singh, M.; Verma, N.; Garg, A.K.; Redhu, N. Urea biosensors. Sens. Actuators B Chem. 2008, 134, $345-351$. [CrossRef]

16. Syu, M.J.; Chang, Y.S. Ionic effect investigation of a potentiometric sensor for urea and surface morphology observation of entrapped urease/polypyrrole matrix. Biosens. Bioelectron. 2009, 24, 2671-2677. [CrossRef] [PubMed]

17. Herlem, B.G.; Lakard, S.; Antoniou, A.; Fahys, B. Urea potentiometric biosensor based on modified electrodes with urease immobilized on polyethylenimine films. Biosens. Bioelectron. 2004, 19, 1641-1647.

18. Lakard, B.; Magnin, D.; Deschaume, O.; Vanlancker, G.; Glinel, K.; Demoustier-Champagne, S.; Nysten, B.; Jonas, A.M.; Bertrand, P.; Yunus, S. Urea potentiometric enzymatic biosensor based on charged biopolymers and electrodeposited polyaniline. Biosens. Bioelectron. 2011, 26, 4139-4145. [CrossRef] [PubMed]

19. Das, G.; Yoon, H.H. Amperometric urea biosensors based on sulfonated graphene/polyaniline nanocomposite. Int. J. Nanomed. 2015, 10, 55-66.

20. Jia, W.Z.; Su, L.; Lei, Yu. Pt nanoflower/polyaniline composite nanofibers based urea biosensor. Biosens. Bioelectron. 2011, 30, 158-164. [CrossRef] [PubMed]

21. Pan, C.W.; Chou, J.C.; Sun, T.P.; Hsiung, S.K. Solid-state urea biosensor based on the differential method. IEEE Sens. J. 2006, 6, 269-275.

22. Slaugther, G. A gold interdigitated microelectrodes fabricated on polyhydroxybutyrate substrate for the determination of urea using impedimetric measurements. IEEE Sens. J. 2012, 12, 821-826. [CrossRef]

23. Laurinavicius, V.; Razumiene, J.; Gureviciene, V. Bioelectrochemical conversion of urea on carbon black electrode and application. IEEE Sens. J. 2013, 13, 2208-2213. [CrossRef]

24. Chou, N.H.; Chou, J.C.; Sun, T.P.; Hsiung, S.K. Measurement and comparison of potentiometric selectivity coefficients of urea biosensors based on ammonium ion-selective electrodes. IEEE Sens. J. 2005, 5, 1362-1368. [CrossRef]

25. Mahadeva, S.K.; Kim, J. Porous tin-oxide-coated regenerated cellulose as disposable and low-cost alternative transducer for urea detection. IEEE Sens. J. 2013, 13, 2223-2228. [CrossRef]

26. Li, L.; Wang, Y.Q.; Pan, L.J.; Shi, Y.; Cheng, W.; Shi, Y.; Yu, G.H. A nanostructured conductive hydrogels-based biosensor platform for human metabolite detection. Nano Lett. 2015, 15, 1146-1151. [PubMed]

27. Li, L.; Shi, Y.; Pan, L.J.; Shi, Y.; Yu, G.H. Rational design and applications of conducting polymer hydrogels as electrochemical biosensors. J. Mater. Chem. B. 2015, 3, 2920-2930. [CrossRef]

28. Zhao, Y.; Liu, B.; Pan, L.J.; Yu, G.H. 3D nanostructured conductive polymer hydrogels for high-performance electrochemical devices. Energy Environ. Sci. 2013, 6, 2856-2870. [CrossRef] 
29. Vering, T.; Adam, S.; Drewer, H.; Dumschat, C.; Steinkuhl, R.; Schulze, A.; Siegel, E.G.; Knoll, M. Wearable microdialysis system for continuous in vivo monitoring of glucose. Analyst 1998, 123, 1605-1609. [CrossRef] [PubMed]

30. Tang, Z.P.; Du, X.G.; Louie, R.; Kost, G.J. Effect of drugs on glucose measurements with handheld glucose meters and a portable glucose analyzer. Am. J. Clin. Pathol. 2000, 113, 75-86. [CrossRef] [PubMed]

31. Ahmadi, M.M.; Jullien, G.A. A wireless-implantable microsystem for continuous blood glucose monitoring. IEEE Trans. Biomed. Circuits Syst. 2009, 3, 169-180. [CrossRef] [PubMed]

32. Lucani, D.; Cataldo, G.; Cruz, J.; Villegas, G.; Wong, S. A portable ECG monitoring device with bluetooth and holter capabilities for telemedicine applications. In Proceedings of the 28th Annual International Conference on Engineering in Medicine and Biology Society, New York, NY, USA, 29-30 August 2006; pp. 5244-5247.

33. Wen, C.; Yeh, M.F.; Chang, K.C.; Lee, R.G. Real-time ECG tele-monitoring system design with mobile phone platform. Measurement 2008, 41, 463-470. [CrossRef]

34. Jaw, F.S.; Tseng, Y.L.; Jang, J.K. Modular design of a long-term portable recorder for physiological signals. Measurement 2010, 43, 1363-1368. [CrossRef]

35. Chou, N.H.; Chou, J.C.; Sun, T.P.; Hsiung, S.K. Study on the disposable urea biosensors based on PVC-COOH membrane ammonium ion-selective electrodes. IEEE Sens. J. 2006, 6, 262-268. [CrossRef]

36. Sekhar, P.K.; Brosha, E.L. Trace detection of 2, 4, 6-trinitrotoluene using electrochemical gas sensor. IEEE Sens. J. 2015, 15, 1624-1629. [CrossRef]

37. Li, H.; Mu, X.; Yang, Y.; Mason, A.J. Low power multimode electrochemical gas sensor array system for wearable health and safety monitoring. IEEE Sens. J. 2014, 14, 3391-3399. [CrossRef]

38. Nandakumar, V.; Bishop, D.; Alonas, E.; LaBelle, J.; Joshi, L.; Alford, T.L. A Low-Cost Electrochemical Biosensor for Rapid Bacterial Detection. IEEE Sens. J. 2011, 11, 210-216. [CrossRef]

39. Kim, C.S.; Lee, C.H.; Fiering, J.O.; Ufer, S.; Scarantino, C.W.; Nagle, H.T. Manipulation of microenvironment with a built-in electrochemical actuator in proximity of a dissolved oxygen microsensor. IEEE Sens. J. 2004, 4, 568-575. [CrossRef]

40. Wang, W.S.; Huang, H.Y.; Chen, S.C.; Ho, K.C.; Lin, C.Y.; Chou, T.C.; Wu, C.H.; Wang, W.F.; Wu, C.F.; Luo, C.H. Real-time telemetry system for amperometric and potentiometric electrochemical sensor. Sensors 2011, 11, 8593-8610. [CrossRef] [PubMed]

41. Chung, W.Y.; Yeh, M.H.; Chen, J.C.; Hsiung, S.K. Design of a low-voltage instrumentation amplifier for enzyme-extended-gate field effect transistor based urea sensor application. In Proceedings of the First IEEE International Workshop on Electronic Design, Test and Applications, Christchurch, New Zealand, 29-31 January 2002; pp. 177-180.

42. Wang, J.Q.; Chou, J.C.; Sun, T.P.; Hsiung, S.K.; Hsiung, G.B. pH-based potentio-metrical flow injection biosensor for urea. Sens. Actuators B Chem. 2003, 91, 5-10. [CrossRef]

43. Ma, W.J.; Huang, H.Y.; Luo, C.H. A low power analog front-end (AFE) circuit dedicated for driving bio-electrochemical sensors and peripheral device. In Proceedings of the IEEE Biomedical Circuits and Systems (BioCAS) Conference, Hsinchu, Taiwan, 28-30 November 2012; pp. 120-123.

44. Lambrechts, M.; Sansen, W. Biosensors: Microelectrochemical. Devices, 1st ed.; Institute of Physics Publishing: Bristol, UK, 1992.

45. Bard, A.J.; Faulkner, L.R. Electrochemical Methods: Fundamentals and Applications, 2nd ed.; Wiley: Hoboken, NJ, USA, 2001.

46. Texas Instrument. MASP430F149 Texas Instrument Mixed Signal Microcontroller, 2011. Available online: http:/ / www.ti.com/lit/ds/symlink/msp430f149 (accessed on 18 November 2015).

47. Huang, C.J.; Lin, J.L.; Chen, P.H.; Syu, M.J.; Lee, G.B. A multi-functional electrochemical sensing system using micro-fluid technology for detection of urea and creatinine. Electrophoresis 2011, 32, 931-938. [CrossRef] [PubMed]

(C) 2016 by the authors; licensee MDPI, Basel, Switzerland. This article is an open access article distributed under the terms and conditions of the Creative Commons by Attribution (CC-BY) license (http://creativecommons.org/licenses/by/4.0/). 